\title{
Role of Nicotinic Acetylcholine Receptor on Efferent Inhibition in Cochlear Hair Cell
}

\author{
Gi Jung Im \\ Department of Otolaryngology-Head and Neck Surgery, Korea University College of Medicine, Seoul, Korea
}

$\begin{array}{ll}\text { Received } & \text { November 19, } 2012 \\ \text { Revised } & \text { December 8, 2012 } \\ \text { Accepted } & \text { December 11, } 2012\end{array}$

Address for correspondence

Gi Jung Im, MD, PhD

Department of Otolaryngology-Head and Neck Surgery, Korea University

College of Medicine,

73 Inchon-ro, Seongbuk-gu,

Seoul 136-705, Korea

Tel $+82-2-920-5486$

Fax $+82-2-925-5233$

E-mail logopas@korea.ac.kr
The $\alpha 9 \alpha 10$ nicotinic acetylcholine receptors (nAChRs) mediates efferent inhibition of hair cell function within the auditory sensory organ. Gating of the nAChRs leads to activation of calcium-dependent potassium channels to hyperpolarize the hair cell. In efferent system, main calcium providers to SK channel are nAChR and synaptic cistern, which contribution to efferent inhibition is different between avian and mammalian species. Calcium permeation is more effective in nAChRs of mammalian cochlea than avian cochlea, and mammalian calcium permeability of $n A C h R s$ is about 3 times more than avian hair cell. Thus, mammalian $n A C h R s$ is a main component of efferent inhibition in cochlear hair cell system.

Korean J Audiol 2012;16:108-113

KEY WORDS: Nicotinic receptor · Hair cell · Cochlea $\cdot$ Acetylcholine $\cdot$ Calcium.

\section{Introduction}

In mammals, hearing is defined as converting sound waves into electrical signals by two types of mechanotransducer hair cells, inner hair cell (IHC), and outer hair cell (OHC). These cells are comparable to 'tall' and 'short' hair cell in chicken cochlea (basilar papilla).

Medial olivocochlear (MOC) efferent neurons are located in the superior olivary complex and project via myelinated fibers to make synaptic contacts directly onto the base of OHCs. Before the onset of hearing, IHCs are transiently innervated by MOC efferents as well. Although gamma-aminobutyric acid, calcitonin gene related peptide, and opioid peptides are also present in MOC terminals, acetylcholine (ACh) is considered to be the primary transmitter of the efferents. ${ }^{1} \mathrm{ACh}$ released by efferent terminals binds postsynaptically to the highly calcium permeable $\alpha 9 \alpha 10$ nicotinic acetylcholine receptors (nAChRs). This leads to the subsequent activation of calcium dependent $\mathrm{SK} \mathrm{K}^{+}$channels and $\mathrm{K}^{+}$efflux, hyperpolarizing the hair cell (Fig. 1). ${ }^{2)}$ Hyperpolarization of OHCs eventually induces inhibition of neural signals from afferent fibers and inner hair cells, thus efferent inhibition provides feedback and modulation of the afferent signals. ${ }^{3)}$ Efferent inhibition offers the potential to improve signal detection in noisy environment, to selectively attend to particular signals, and to protect the cochlea from loud sound damage.

In this review, author provide the information about 1) mechanism of efferent inhibition, 2) basic information of electrophysiology such as patch clamp, 3 ) role of nAChRs on efferent inhibition, especially calcium permeability of receptor.

\section{Mechanism of Efferent Inhibition}

\section{Efferent innervation of the cochlea}

$\mathrm{MOC}$ efferent neurons are located in the superior olivary complex of the brainstem and project to the cochlea. Lateral olivocochlear efferent (LOC) originates from the lateral superior olivary nucleus, and projects to IHCs in the ipsilateral side. Efferent fibers are divided into the uncrossed and crossed olivocochlear bundles, with the latter crossing the midline near the floor of the fourth ventricle. Although both the LOC and MOC contain crossed (contralateral) and uncrossed (ipsilateral) fibers, in most mammalian species the majority of LOC fibers project to the ipsilateral cochlea, while the majority of the MOC fibers project to the contralateral cochlea.

Within two week from birth, the rat's MOC efferents transiently innervate IHCs prior to the onset of hearing. ${ }^{5)}$ Thus, the recordings of IHCs and ACh puff stimulation of IHCs can 
mimic efferent response of OHCs in the early developmental period. IHCs of neonatal rats are useful for the efferent inhibition research, because of the easy dissection and transient innervation of MOC efferents. These efferent axosomatic synapses with immature IHCs are supposed to have a functional importance since, first, the efferent synapse on immature IHCs is functional ${ }^{6)}$ and second, axosomatic synapses reappear transiently in adulthood after the IHC has been disconnected from auditory dendrites by excitotoxic injury. ${ }^{7)}$ These results have suggested that the transient efferent innervation may play a role in the functional maturation and recovery of the cochlear hair cells. ${ }^{5)}$

\section{Acetylcholine induces hyperpolarizing inhibitory synaptic potentials}

Brainstem neurons project to ${ }^{4)}$ and suppress the response of the cochlea to sound. ${ }^{8)}$ These efferent neurons are cholinergic, and a considerable list of evidence supports the role of ACh as the efferent inhibitory transmitter. ${ }^{9-11)}$ Intracellular recordings revealed that efferent activity caused hyperpolarizing inhibitory postsynaptic potentials (IPSPs) in hair cells. ${ }^{12)}$ Application of ACh to hair cells isolated from the chick's cochlea causes a biphasic voltage change that results from the sequential activation of ligand-gated cation channels, followed by current through calcium-activated potassium channels. A novel nAChR mediates this response. The calcium-dependent potassium channels activated in hair cells by ACh (SK channel) are apamin-sensitive and of small conductance. ${ }^{13-16)}$

\section{Efferent coupling in both nAChRs and calcium dependent SK K ${ }^{+}$channels}

Efferent neurons release ACh to inhibit sensory hair cells of the inner ear. As implied by their voltage-dependence, calcium entry through the nAChRs triggers calcium-dependent potassium current to hyperpolarize hair cells. Efferent activity induces long-lasting hyperpolarizing IPSPs in cochlear hair cells, and this efferent activity consists of a brief depolarization preceding a much larger, long-lasting hyperpolarization. Thus ACh causes a biphasic change in the membrane conductance of mammalian cochlear hair cells. Recent studies revealed that first inward current through nAChRs makes a brief depolarization, and next potassium outward current through SK channel makes a much larger, long-lasting hyperpolarization. Systematic coupling between nAChRs and calcium dependent SK $\mathrm{K}^{+}$channels play an important role in efferent inhibition of cochlear hair cells (Fig. 1B).

\section{Synaptic cistern as intracellular calcium store}

Synaptic cistern, a near membrane endoplasmic reticulum, is co-extensive with the efferent synaptic contact. The internal calcium stores may participate in efferent inhibition. Prolonged ACh application induced the irregular, highly variable waveform of the calcium-induced calcium release (CICR). CICR is a form of sporadic calcium release from the synaptic cistern. In the surface of synaptic cistern, there are two major ion channels: one is sarcoplasmic/endoplasmic reticulum calcium ATPase (SERCA), and the other is a ryanodine receptor. SERCA calcium pump moves calcium from the cytoplasm to the synaptic cistern, and refills calcium into the synaptic cistern. Ryanodine receptor provides additional calcium from synaptic cistern to subsynaptic space, and evokes calcium-induced SK channel activation. Thus, this sporadic calcium release through ryanodine receptor is CICRs. An interesting feature of the synaptic cistern is the difference of width de-

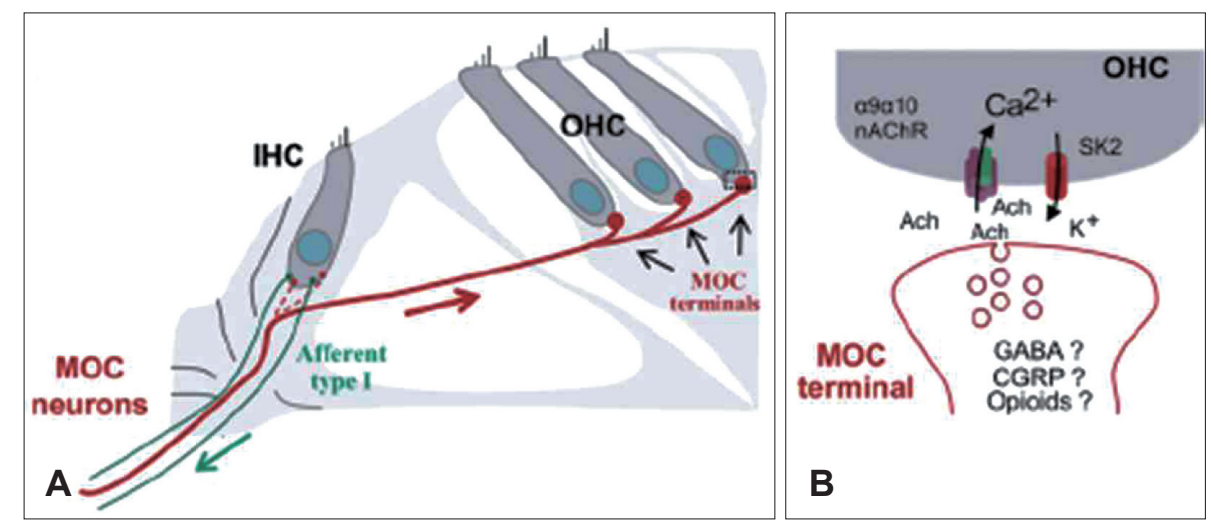

Fig. 1. MOC efferent pathway and function. Schematics showing the peripheral projection of MOC fibers (A) and the efferent synapse onto OHCs in the mature organ of Corti (B). MOC efferent neurons are located in the superior olivary complex and project via myelinated fibers to make synaptic contacts directly onto the base of OHCs. Before the onset of hearing, IHCs are innervated as well (A, dashed red line). ACh released by efferents binds postsynaptically to the highly calcium permeable a9a10 nAChRs, and makes calcium coming into hair cell through nAChRs. This leads to the subsequent activation of calcium dependent $\mathrm{SK} \mathrm{K}^{+}$channels and $\mathrm{K}^{+}$efflux, hyperpolarizing the hair cell (adapted from Wersinger, et al., 2011). MOC: medial olivocochlear, OHC: outer hair cell, IHC: inner hair cell, ACh: acetylcholine, GABA: gamma-aminobutyric acid, CGRP: calcitonin gene related peptide, nAChRs: a9a10 nicotinic acetylcholine receptors. 
pending upon species. For example, extensive cisterna was shown in chick hair cells, and the narrow cisterna was observed in mammalian hair cells. However, functional study will be needed to reveal the difference of synaptic cistern between birds and mammals.

\section{Basic Information of Electrophysiology Such as Patch Clamp}

\author{
Recording of chick auditory organ (basilar papilla) and \\ rat cochlea
}

We obtained patch-clamp recordings from the inner hair cells of the apical turns in the cochlea excised from young (P9-P10) rats, in which efferent synaptic input is commonly found. ${ }^{17,18)}$ The auditory organ (basilar papilla) was dissected from the temporal bone of embryonic chickens (17-20 d in ovo). After 5-10 min of exposure to protease (Sigma-Aldrich Type XXIV, $0.1 \mathrm{mg} / \mathrm{mL}$ ) in buffered saline, the tegmentum vasculosum and tectorial membrane were removed, exposing the sensory hair cells. The basilar papilla or cochlea was secured to a coverslip by small spring clips (made from fine insect pins) and transferred to a recording chamber and viewed with differential interference contrast using a $40 \times$ water immersion objective and a camera with contrast enhancement (Fig. 2A).

Short hair cells were recorded in a region corresponding to $500-1000 \mathrm{~Hz}$, along the tonotopically organized basilar papilla of the chicken $(0.25-0.5 \mathrm{~mm}$, the distance from the apical tip toward the base). These cells were confirmed to be short hair cells by their position farthest from the neural limbus, where they receive predominantly efferent innervation. ${ }^{19)}$ Finally, these cells responded to ACh with a combination of ligand-gated cation current, followed by $\mathrm{Ca}^{2+}$-dependent potassium current through apamin-sensitive ("SK-like") potassium channels, as demonstrated previously. ${ }^{20)}$ Patch and puffer pipettes $(3-5 \mathrm{M} \Omega$, coated with Sylgard silicon elastomer and fire-polished) were mounted on piezoelectric manipulators for positioning on the hair cells. Voltage-clamp recordings were obtained using an Axopatch 200B, running under Clampex software. Recordings were made at room temperature. Whole-cell, giga-ohm seal intracellular recordings were made on 'short' (abneural) hair cells approximately at the midpoint of the $4 \mathrm{~mm}$ long basilar papilla (chicken auditory organ) from late-stage embryos (E17-20) using intracellular cesium/BAPTA $(10 \mathrm{mM})$ and extracellular apamin $(300 \mathrm{nM})$ to minimize the SK current (Fig. 2B). Puff application of ACh ( $1 \mathrm{mM}, 500 \mathrm{~ms}$ ) elicited inward currents at negative membrane potentials that reversed near $0 \mathrm{mV}$, which means calcium dominant ion channel. The reversal potential was determined using 'ramp' voltage commands from -100 to +100 $\mathrm{mV}, 200 \mathrm{~ms}$ duration, designed to coincide with the steady maximal response to ACh. Control I-V values were subtracted from those obtained in the presence of ACh to measure the reversal potential of the ACh evoked current (Fig. 3).

\section{Measurement of reversal potential and calcium permeability}

To measure reversal potentials as a function of external calcium, we used an extracellular solution containing $100 \mathrm{mM}$ $\mathrm{NaCl}, 5.8 \mathrm{mM} \mathrm{KCl}, 0.1-10 \mathrm{mM} \mathrm{CaCl}_{2}, 5.6 \mathrm{mM}$ d-glucose, and $10 \mathrm{mM}$ Hepes buffer ( $\mathrm{pH}$ 7.4), with osmolality adjusted to 300-320 mosmol/kg with sucrose. To measure current through the cationic nAChR only, without contaminating SK current, we used a pipette solution containing $140 \mathrm{mM} \mathrm{CsCl}, 3.5 \mathrm{mM}$ $\mathrm{MgCl}_{2}, 10 \mathrm{mM}$ BAPTA-AM, $5 \mathrm{mM}$ Hepes buffer, and 2.5 $\mathrm{mM} \mathrm{Na}{ }_{2} \mathrm{ATP}$, with $\mathrm{pH}$ adjusted to 7.2 with $\mathrm{CsOH}$. Apamin (300 $\mathrm{nM}$ ) was added to the external saline to further minimize calcium-activated SK currents. The experiment was designed to study the voltage dependence of the cationic nAChR currents and/or the changes in the current reversal potential. Thus $\mathrm{KCl}$ was replaced by $\mathrm{CsCl}$ to eliminate voltage-dependent $\mathrm{K}^{+}$ currents. $^{21)}$
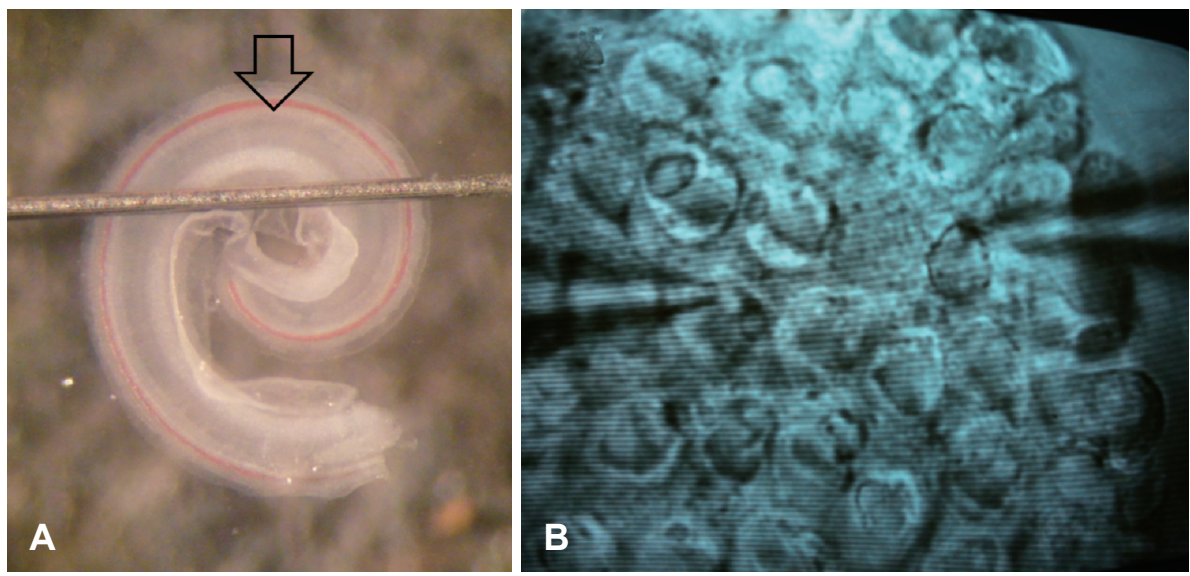

Fig. 2. Preparation of cochlea and recording of hair cell. A: Apical turns of the cochlea excised from young (P9-P10) rats for patch-clamp recordings from inner hair cells. Inner hair cells are usually located medial side to cochlear vascular supply (arrow). B: Whole-cell, giga-ohm seal intracellular recordings were made on 'short' (abneural) hair cells approximately at the midpoint of the $4 \mathrm{~mm}$ long basilar papilla (right electrode). Puff application of ACh (1 mM, 500 $\mathrm{ms}$ ) elicited inward calcium currents and long-lasting hyperpolarization of hair cell (left electrode). ACh: acetylcholine. 

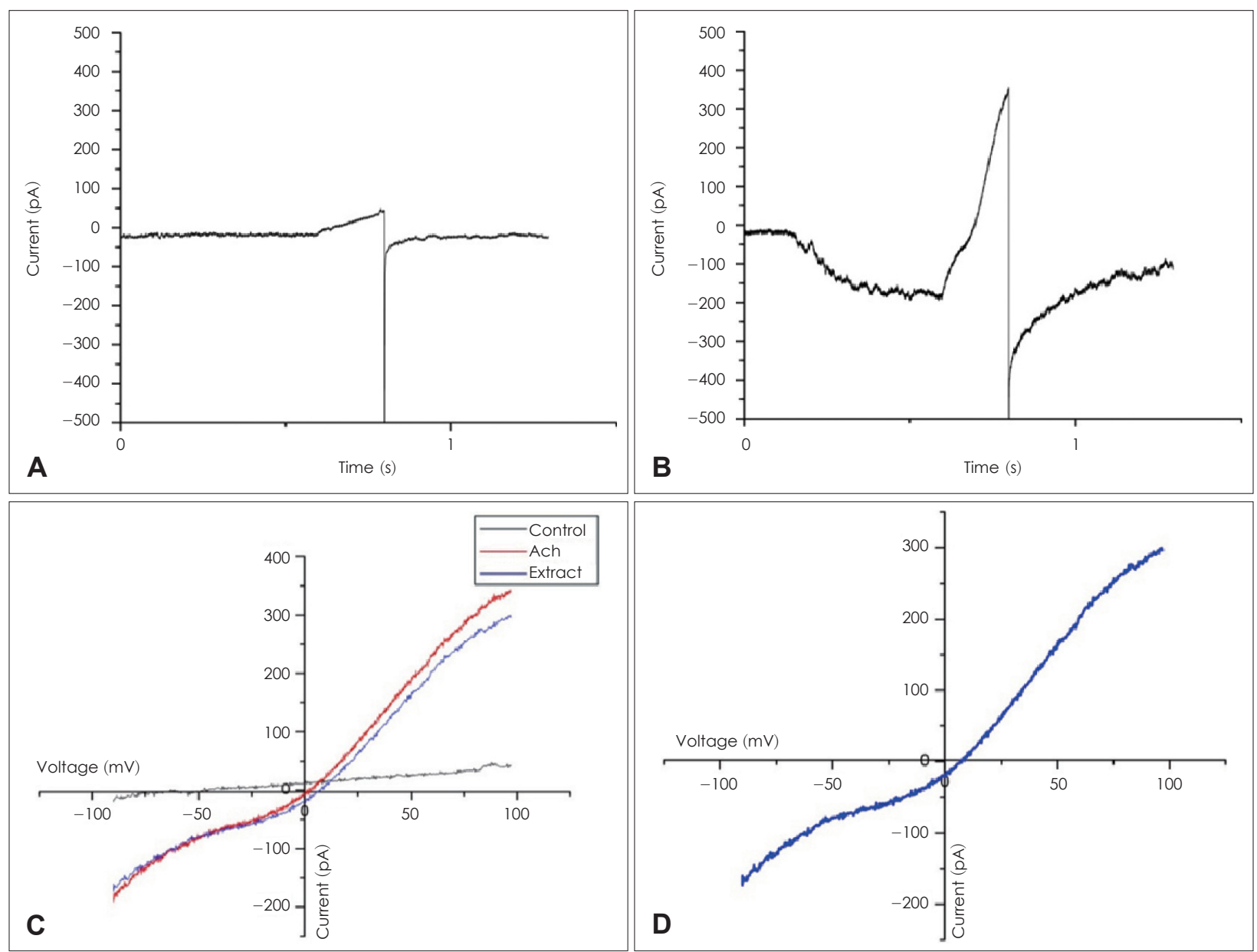

Fig. 3. Current produced by a $200 \mathrm{~ms}$ voltage ramp from -100 to $+100 \mathrm{mV}$ in $1 \mathrm{mM}$ external calcium. A: Control ramp current (Cs-BAPTA internal, apamin external). B: Ramp current during 500 ms 'puff' of $1 \mathrm{mM}$ ACh. C: Ramp IV curves. D: ACh-evoked ramp current obtained by subtraction of control ramp current from that during ACh exposure. BAPTA: 1,2-bis(o-aminophenoxy)ethane-N,N,N',N'-tetraacetic acid, Cs: cesium chloride, ACh: acetylcholine.

The relative $\mathrm{Ca}^{2+}$ to monovalent permeability (pCa/pMono) was evaluated by analyzing the shift in the reversal potential $\left(\mathrm{E}_{\mathrm{rev}}\right)$ as a function of the increase in the extracellular $\mathrm{Ca}^{2+}$ concentration. Permeability ratios were calculated for each recorded cell and then averaged.

\section{Role of Nicotinic Acetylcholine Receptors on Efferent Inhibition}

Efferent cholinergic inhibition of mammalian and avian auditory hair cells is thought to be mediated by nAChRs. Gating of the nAChR leads to activation of calcium-dependent potassium channels to hyperpolarize the hair cell. Heterologous expression in Xenopus oocytes has shown that mammalian (rat) $\alpha 9 \alpha 10 \mathrm{nAChRs}$ have a substantial permeability to calcium $(\mathrm{pCa} / \mathrm{pNa}-9)$ similar to that of the native $\mathrm{nAChR}$ $(\mathrm{pCa} / \mathrm{pNa}-8){ }^{22)}$ In contrast, avian (chicken) $\alpha 9 \alpha 10$ in oocytes is significantly less $\mathrm{Ca}^{2+}$-permeable $(\mathrm{pCa} / \mathrm{pNa}<3)$, and here we provide a comparison with the properties of the native cell $\mathrm{nAChR}$ between the avian and mammalian species. In most cells, a standard voltage-step protocol also was used. These measurements (5-8 cells each) were carried out in 0.1 , 1 , and $3 \mathrm{mM}$ calcium saline. The ACh-evoked current was largest in $1 \mathrm{mM}$ calcium, and displayed sharp outward rectification. Outward rectification was more pronounced in higher calcium concentrations and could be reduced by conditioning depolarization, with both observations supporting a 'calcium permeation and block' effect. There was no significant effect of calcium on reversal potential for these concentrations, but $\mathrm{I}-\mathrm{V}$ curves tend to show more positive $\mathrm{E}_{\mathrm{rev}}$ in higher external calcium (Fig. 4A). From the extended equation, the $\mathrm{Ca}^{2+}$ permeability relative to that of the dominant monovalent cation was calculated as 2.6. The reversal potential of ACh-evoked currents of rat inner hair cells had a steeper slope, and a calculated $\mathrm{pCa} / \mathrm{pMono}$ of 8 . Thus, like the recombinant avian $\alpha 9 \alpha$ 10 , the native chicken hair cell nAChR appears to have a rela- 

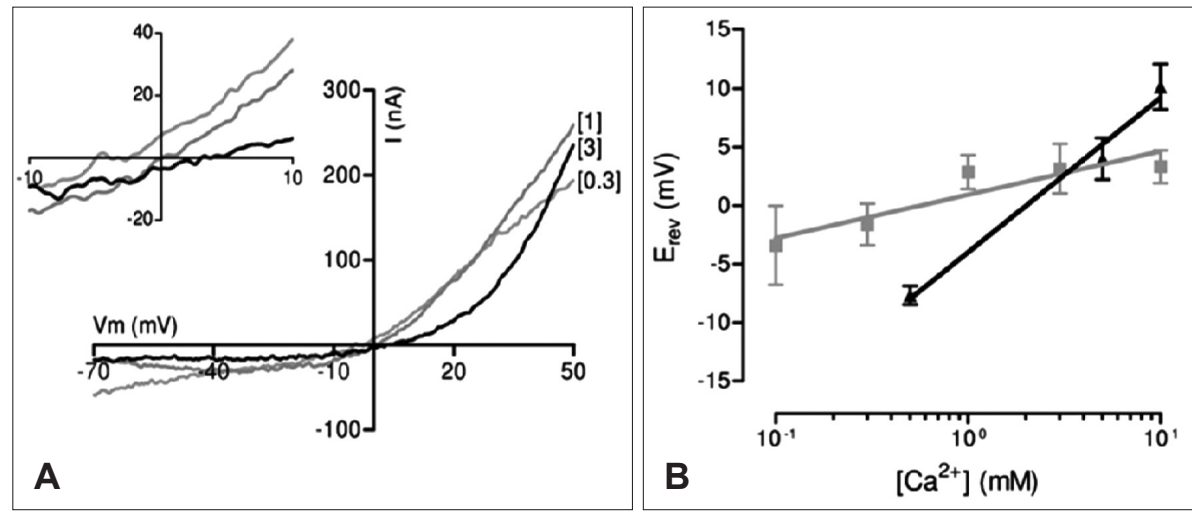

Fig. 4. Chicken short hair cell $n A C h R$ has lower relative calcium permeability than that of rat. A: I-V curves obtained by voltage ramp protocols used to define the reversal potentials in external calcium concentrations of $0.1,1$, and $3 \mathrm{mM}$ (Inset). Magnification near the $\mathrm{E}_{\text {rev. }}$ The higher calcium concentration, the more positive $\mathrm{E}_{\mathrm{rev}}$. B: Average $( \pm \mathrm{SEM}) \mathrm{E}_{\mathrm{rev}}$ as a function of external calcium concentration in chicken short hair cells (gray squares, 5-8 cells per point), compared with previously published data for rat inner hair cells (black triangles)(adapted from Marcela and Gijung Im, 2012). nAChRs: a9a10 nicotinic acetylcholine receptors, SEM: standard error of the mean.

tively low permeability to calcium. In these results, the mammalian cochlear nAChRs are approximately 3 times more permeable to calcium compared with the avian nAChRs (Fig. 4B). Considering the similar functional power of efferent inhibition between the avian and mammalian species, relative contribution of synaptic cistern to activate SK channel as calcium provider may be different, and more powerful synaptic cistern of the avian species may compensate lower avian nAChRs permeability. Future study should focus on the functional measurement of synaptic cistern and other contributable factor to efferent inhibition.

\section{Conclusion}

1) Efferent inhibition: calcium influx $(n A C h R)+$ potassium outflux (SK channel).

2) $E_{\text {rev }}$ of avian nAChR moved to positive holding voltage according to $\mathrm{Ca}^{2+}$ concentration, but is much more flat than $\mathrm{E}_{\text {rev }}$ of rat $\mathrm{nAChR}$. This result shows that avian $\mathrm{nAChR}$ is less permeable to calcium than mammals.

3) Calcium permeation is more effective in nAChRs of mammalian cochlea than avian cochlea (about 3 times more in native cochlear hair cell).

4) In efferent system, main calcium providers to SK channel are $\mathrm{nAChR}$ and synaptic cistern, which contribution to efferent inhibition is different between avian and mammalian species.

\section{Acknowledgments}

This work is supported by the Korea University Research Fund (K1220291) and the National Research Foundation of Korea Grant NRF-2010-013-E00015. Special thanks to Fuchs PA, Johns Hopkins University School of Medicine, for kind advice.

\section{REFERENCES}

1) Schuknecht HF, Churchill JA, Doran R. The localization of acetyl- cholinesterase in the cochlea. AMA Arch Otolaryngol 1959;69:54959.

2) Wersinger E, Fuchs PA. Modulation of hair cell efferents. Hear Res 2011;279:1-12.

3) Brown MC, Nuttall AL. Efferent control of cochlear inner hair cell responses in the guinea-pig. J Physiol 1984;354:625-46.

4) Rasmussen GL. The olivary peduncle and other fiber projections of the superior olivary complex. J Comp Neurol 1946;84:141-219.

5) Simmons DD. Development of the inner ear efferent system across vertebrate species. J Neurobiol 2002;53:228-50.

6) Glowatzki E, Fuchs PA. Cholinergic synaptic inhibition of inner hair cells in the neonatal mammalian cochlea. Science 2000;288:2366-8.

7) Puel JL, Saffiedine S, Gervais d'Aldin C, Eybalin M, Pujol R. Synaptic regeneration and functional recovery after excitotoxic injury in the guinea pig cochlea. C R Acad Sci III 1995;318:67-75.

8) Galambos R. Suppression of auditory nerve activity by stimulation of efferent fibers to cochlea. J Neurophysiol 1956;19:424-37.

9) Norris $\mathrm{CH}$, Guth PS. The release of acetylcholine (ACH) by the crossed olivo-cochlear bundle (COCB). Acta Otolaryngol 1974;77:318-26.

10) Jasser A, Guth PS. The synthesis of acetylcholine by the olivo-cochlear bundle. J Neurochem 1973;20:45-53.

11) Guth PS, Norris CH, Bobbin RP. The pharmacology of transmission in the peripheral auditory system. Pharmacol Rev 1976;28:95125 .

12) Flock A, Russell I. Efferent nerve fibres: postsynaptic action on hair cells. Nat New Biol 1973;243:89-91.

13) Doi $\mathrm{T}$, Ohmori H. Acetylcholine increases intracellular $\mathrm{Ca} 2+$ concentration and hyperpolarizes the guinea-pig outer hair cell. Hear Res 1993;67:179-88.

14) Nenov AP, Norris C, Bobbin RP. Acetylcholine response in guinea pig outer hair cells. II. Activation of a small conductance $\mathrm{Ca}(2+)$-activated K+ channel. Hear Res 1996;101:149-72.

15) Yamamoto T, Kakehata S, Yamada T, Saito T, Saito H, Akaike N. Effects of potassium channel blockers on the acetylcholine-induced currents in dissociated outer hair cells of guinea pig cochlea. Neurosci Lett 1997;236:79-82.

16) Yuhas WA, Fuchs PA. Apamin-sensitive, small-conductance, calcium-activated potassium channels mediate cholinergic inhibition of chick auditory hair cells. J Comp Physiol A 1999;185:455-62.

17) Glowatzki E, Fuchs PA. Transmitter release at the hair cell ribbon synapse. Nat Neurosci 2002;5:147-54.

18) Lioudyno M, Hiel H, Kong JH, Katz E, Waldman E, ParameshwaranIyer S, et al. A "synaptoplasmic cistern" mediates rapid inhibition of cochlear hair cells. J Neurosci 2004;24:11160-4.

19) Zidanic M. Cholinergic innervation of the chick basilar papilla. J 
Comp Neurol 2002;445:159-75.

20) Fuchs PA, Murrow BW. Cholinergic inhibition of short (outer) hair cells of the chick's cochlea. J Neurosci 1992;12:800-9.

21) Lipovsek M, Im GJ, Franchini LF, Pisciottano F, Katz E, Fuchs PA, et al. Phylogenetic differences in calcium permeability of the auditory hair cell cholinergic nicotinic receptor. Proc Natl Acad Sci U S A 2012;109:4308-13.

22) Gómez-Casati ME, Fuchs PA, Elgoyhen AB, Katz E. Biophysical and pharmacological characterization of nicotinic cholinergic receptors in rat cochlear inner hair cells. J Physiol 2005;566(Pt 1):103-18. 